\title{
Electronic Cigarette Use and Respiratory Symptoms in Adolescents
}

\author{
Rob McConnell ${ }^{1}$, Jessica L. Barrington-Trimis ${ }^{1}$, Kejia Wang ${ }^{1}$, Robert Urman ${ }^{1}$, Hanna Hong ${ }^{2}$, Jennifer Unger ${ }^{1}$, \\ Jonathan Samet ${ }^{1}$, Adam Leventhal ${ }^{1}$, and Kiros Berhane ${ }^{1}$ \\ ${ }^{1}$ Department of Preventive Medicine, Keck School of Medicine, University of Southern California, Los Angeles, California; and ${ }^{2}$ Division of \\ Pulmonary Medicine, Department of Pediatrics, Children's Hospital Los Angeles, Los Angeles, California
}

\begin{abstract}
Rationale: Rates of adolescent electronic (e-) cigarette use are increasing, but there has been little study of the chronic effects of use. Components of e-cigarette aerosol have known pulmonary toxicity.

Objectives: To investigate the associations of e-cigarette use with chronic bronchitis symptoms and wheeze in an adolescent population.

Methods: Associations of self-reported use of e-cigarettes with chronic bronchitic symptoms (chronic cough, phlegm, or bronchitis) and of wheeze in the previous 12 months were examined in 2,086 Southern California Children's Health Study participants completing questionnaires in 11th and 12th grade in 2014.
\end{abstract}

Measurements and Main Results: Ever e-cigarette use was reported by 502 (24.0\%), of whom 201 (9.6\%) used e-cigarettes during the last 30 days (current users). Risk of bronchitic symptoms was increased by almost twofold among past users (odds ratio [OR],
1.85; 95\% confidence interval [CI], 1.37-2.49), compared with never-users, and by 2.02 -fold (95\% CI, 1.42-2.88) among current users. Risk increased with frequency of current use (OR, 1.66; 95\% CI, 1.02-2.68) for 1-2 days and 2.52 (95\% CI, 1.56-4.08) for 3 or more days in past 30 days compared with never-users. Associations were attenuated by adjustment for lifetime number of cigarettes smoked and secondhand smoke exposure.

However, risk of bronchitic symptoms among past e-cigarette users remained elevated after adjustment for relevant potential confounders and was also observed among never-cigarette users (OR, 1.70; 95\% CI, 1.11-2.59). There were no statistically significant associations of e-cigarette use with wheeze after adjustment for cigarette use.

Conclusions: Adolescent e-cigarette users had increased rates of chronic bronchitic symptoms. Further investigation is needed to determine the long-term effects of e-cigarettes on respiratory health.

Keywords: e-cigarettes; bronchitis; smoking in young adults
Use of electronic (e-) cigarettes, including vape pens, e-hookah, e-cigars, or other electronic nicotine delivery systems has increased rapidly worldwide in recent years. In the United States, prevalence of e-cigarette use in the previous 30 days among high school students (ninth to 12th grade) in the U.S. National Youth Tobacco Survey increased from $1.5 \%$ in 2011 to $16.0 \%$ in 2015 (1) and in 2014 was estimated to be a
\$2 billion (and rapidly growing) market (2). The diversity of e-cigarette products, in particular of products with flavorings, is also increasing at a rapid rate. As of January 2014, there were 466 distinct brands of electronic nicotine products and at least 7,764 unique flavors (2).

There has been little study of the chronic health effects of e-cigarettes $(3,4)$. However, ecigarettes produce exposures with known toxicity to the lung. These include flavorings, volatile aldehydes, and oxidant metals present in e-cigarette aerosol (5-8). In in vitro study of human airway epithelial cells and in mouse lungs, e-cigarette vapor produced oxidative stress and inflammatory effects, and decreased cell viability (9). Moreover, e-cigarettes deliver an aerosol of ultrafine particles to the distal airways and alveoli (10). Therefore, the lung is a likely target organ for health effects of

(Received in original form October 7, 2016; accepted in final form October 27, 2016)

Supported by National Institutes of Health grants P50CA180905, R21HD084812, R01 ES016535, P30ES007048, and P01ES011627; and the Hastings Foundation. The funding organizations had no role in the design and conduct of the study; collection, management, analysis, and interpretation of the data; nor in preparation, review, or approval of the manuscript.

Author Contributions: Conception and design, R.M. Analysis and interpretation, R.M., J.L.B.-T., K.W., R.U., H.H., J.U., J.S., A.L., and K.B. Drafting the manuscript for important intellectual content, R.M., J.L.B.-T., R.U., H.H., J.U., J.S., A.L., and K.B.

Correspondence and requests for reprints should be addressed to Rob McConnell, M.D., Department of Preventive Medicine, 2001 N Soto Street, Room 230D, Los Angeles, CA 90089. E-mail: rmcconne@usc.edu

This article has an online supplement, which is accessible from this issue's table of contents at www.atsjournals.org

Am J Respir Crit Care Med Vol 195, Iss 8, pp 1043-1049, Apr 15, 2017

Copyright $\odot 2017$ by the American Thoracic Society

Originally Published in Press as DOI: 10.1164/rccm.201604-0804OC on November 2, 2016

Internet address: www.atsjournals.org 


\section{At a Glance Commentary}

\section{Scientific Knowledge on the \\ Subject: Rates of adolescent}

electronic (e-) cigarette use are increasing, but there has been little study of the chronic effects of use. Components of e-cigarette aerosol have known pulmonary toxicity.

\section{What This Study Adds to the}

Field: Adolescent e-cigarette users had increased rates of chronic bronchitic symptoms. Further investigation is needed to determine the long-term effects of e-cigarettes on respiratory health.

e-cigarettes. Two recent cross-sectional studies of children found an association of e-cigarette use with increased prevalence of bronchitic symptoms (11) and asthma (12).

Detailed prospective information has been collected on respiratory symptoms in the Southern California Children's Health Study (CHS) (13), a cohort with low rates of cigarette smoking and rapidly increasing use of e-cigarettes. We evaluated the associations of e-cigarette use with wheeze and chronic bronchitic symptoms, which are both common and account for substantial morbidity in children (14). These symptoms have been shown in the CHS and other studies to be associated with smoking and exposure to secondhand tobacco smoke (SHS), ambient air pollution, and other respiratory irritants (14-19). The results of this study were reported at the Society for Research on Nicotine and Tobacco (Philadelphia, Pennsylvania, February 27, 2015).

\section{Methods}

\section{Population}

Participants were initially recruited into the CHS cohort in 2002-2003, when they were in kindergarten or first grade, from entire classrooms in schools in 12 communities in southern California (see the online supplement) (13). The cohort was followed annually through 2008, then every 2 years through 2014. We now report findings from the 2014 survey, when students were in 11th and 12 th grade $(n=2,097 ; 87 \%$ of 2,412 members of the cohort attending schools in the study communities). Of these, 2,086 provided information on e-cigarette use and either wheeze or bronchitic symptoms. Mean age of this sample was 17.3 years (SD, 0.6). Participants completed selfadministered questionnaires at school with study staff supervision.

The study was approved by the University of Southern California institutional review board. Written informed consent was obtained before data collection.

\section{Outcomes}

A child was considered to have had chronic bronchitic symptoms during the previous year, based on the report of a daily cough for 3 months in a row, congestion, or phlegm other than when accompanied by a cold, or bronchitis in the previous 12 months, as previously described (15). Wheeze was assessed based on a report of wheezing or whistling in the chest during the previous 12 months. Information on wheeze severity in the past 12 months was collected, based on any attacks of wheeze, sleep disturbance caused by wheeze, or wheezing severe enough to limit speech to only one or two words at a time between breaths (20). Analyses were based on subjects with complete information on e-cigarette use, including 1,922 subjects also not missing information and not reporting "don't know" regarding bronchitic symptoms, and 2,083 subjects not missing wheeze information. Information on these conditions was collected at each visit during the prior prospective follow-up of the cohort, as previously described (21).

\section{Tobacco Product Use}

The 2014 questionnaire assessed use of tobacco products, including cigarette, cigar, pipe, hookah, and e-cigarettes, based on questions modified from the National Youth Tobacco Survey (22). Students were asked the age at which they had first tried cigarettes or e-cigarettes and the number of days they had used the product in the past 30 days. Participants who had "never tried" a product were classified as "never-users." Those who had used a product, but not in the last 30 days, were classified as "past users." Participants who had used a product on at least 1 of the past 30 days were classified as "current users" of that product. Frequency of current e-cigarette use was categorized as 1-2 days or 3 or more days. In addition, participants reported number of cigarettes smoked in the previous month and the lifetime number of cigarettes smoked.
Lifetime number of cigarettes smoked was categorized as 0 (never-smokers), greater than $0-10,11-99$, and greater than 99 cigarettes.

\section{Covariate Information}

Asthma was based on participant's self-report of ever having had asthma (20). A parentcompleted questionnaire at study entry assessed sociodemographic characteristics, including child's date of birth, sex, ethnicity (Hispanic, non-Hispanic white, other), parental education (highest level of education of either parent, categorized as $<12$ th grade, high school diploma or GED, some college, college degree, or some graduate school or higher), and acculturation based on language of questionnaire (Spanish or English) completed. Information on housing conditions (including a history of mildew or mold or of water damage or flooding in the home while the child lived there, of a gas stove, cockroaches, or carpeting in the home), and ownership of a dog or cat, was collected and updated periodically over the course of follow-up by parent- or childcompleted questionnaire.

Information on SHS exposure inside the home of the child was collected in each questionnaire over the course of follow-up. In 2014, perception of harm of e-cigarette use was assessed by asking whether the participant thought it would be bad for his or her health, and was classified based on whether the participant strongly agreed, agreed, disagreed, or strongly disagreed.

\section{Statistical Analysis}

Logistic regression was used to evaluate the association of bronchitic symptoms and current wheeze with e-cigarette use. Dummy variables were created to assess effects of past and current use, compared with never use, and of frequency of use among current users. The linear trend in effects of frequency of current e-cigarette use was assessed across three categories of use (never-users, 1-2, and 3 or more $\mathrm{d}$ in the previous $30 \mathrm{~d}$ ). Confounding was assessed by including relevant covariates in the model to see if the estimated e-cigarette effect changed by more than $10 \%$. The estimate of e-cigarette associations with the outcomes examined changed more after adjustment for lifetime number of cigarettes smoked than adjustment for other smoking variables (categories of never, past, and current smoking and number of cigarettes smoked in past $30 \mathrm{~d}$ ). Therefore, models were adjusted for lifetime number of cigarettes. In sensitivity analyses, associations of e- 
cigarettes with bronchitic symptoms and wheeze were adjusted for these same conditions in 2010 (before there was widespread use of e-cigarettes) and were restricted to children without symptoms in 2010. Based on previous epidemiologic literature on associations of respiratory irritants with bronchitic symptoms in children (23), interaction terms of e-cigarette use with a dog or cat at home were examined for this outcome. For each outcome, the interactions of sex, ethnicity (Hispanic and non-Hispanic white), and asthma (in separate models) with e-cigarette use were also evaluated by calculating a likelihood ratio test for models with and without the interaction across categories of e-cigarette use. In all models, missing data were assumed to occur at random (see online supplement for additional analytical details).

All analyses assumed a two-sided alternative hypothesis at 0.05 level of significance and were conducted using STATA version 13.1 (StataCorp LLC, College Station, TX).

\section{Results}

There were 502 participants $(24.0 \%)$ who had ever used e-cigarettes; 301 (14.4\%) were past and 201 (9.6\%) current users. Among current users, 107 (53.3\%) used e-cigarettes on 1-2 days monthly and $94(46.8 \%)$ on 3 or more days. Among past and current e-cigarette users, 132 (44.2\%) and 81 (40.5\%), respectively, were never-cigarette users.

Compared with Hispanic white participants, non-Hispanic white youth were more likely to have bronchitic symptoms or wheeze (Table 1). Parental education greater than high school was associated with greater risk of both outcomes. SHS exposure in the home was associated with increased risk of bronchitic symptoms but not of wheeze. Current and noncurrent use of cigarettes was associated with greater risk of each outcome.

A report of bronchitic symptoms or wheeze on the 2010 questionnaire (before e-cigarettes were widely available to this cohort) was each associated with both outcomes on the current (2014) questionnaire (see Table E1 in the online supplement). Other covariates positively associated with both bronchitic symptoms and wheeze included ever asthma (in 2014); hookah, cigar, and pipe use; having a pet cat; and a history of water damage or flooding in the home. Effect estimates for current use of each combustible tobacco product were consistently larger than for past use. Parental completion of the enrollment questionnaire in Spanish was inversely associated with both outcomes. A pet dog in the home was associated only with bronchitic symptoms, and mold or mildew in the home was associated only with wheeze.

Bronchitic symptoms were associated with both past (odds ratio [OR], 1.85; 95\% confidence interval [CI], 1.37-2.49) and current use of e-cigarettes (OR, 2.02; 95\% CI, 1.42-2.88). These estimated effects were robust to adjustment for sociodemographic characteristics (Figure 1). They were attenuated by additional adjustment for lifetime number of cigarettes smoked and SHS exposure in the home (OR, 1.71; 95\% CI, 1.20-2.43 for past use) (OR, 1.41; 95\% CI, 0.92-2.17 for current use). Further adjustment for other tobacco product use, other sociodemographic characteristics, and housing conditions listed in Table E1 did not appreciably change the estimated effect size and the association with past e-cigarette use remained significant (results not shown). We examined interactions of e-cigarette use with sex, ethnicity (Hispanic and non-Hispanic white), and asthma and with a dog or cat in the home, none of which was statistically significant.

The risk of bronchitic symptoms increased with number of days used in the previous 30 days (OR, 1.66; 95\% CI, 1.02-2.68 for $1-2 \mathrm{~d})(\mathrm{OR}, 2.52$; $95 \% \mathrm{CI}, 1.56-4.08$ for $\geqslant 3 \mathrm{~d}$ ), compared with never-e-cigarette users (Figure 2) ( $P$ for trend $<0.001$ ). This

Table 1. Association of Selected Demographic Characteristics and Tobacco Product Use with Bronchitis and Wheeze in the Children's Health Study

\begin{tabular}{|c|c|c|c|c|c|c|}
\hline Characteristic & & $\begin{array}{l}\text { Number ( } \% \text { of } \\
\text { Column Total)* }\end{array}$ & $\begin{array}{c}\text { Bronchitis } \\
{\left[n(\% \text { of Row Total) }]^{\dagger}\right.}\end{array}$ & OR (95\% Cl) & $\begin{array}{c}\text { Current Wheeze } \\
{\left[n(\% \text { of Row Total)] }]^{\dagger}\right.}\end{array}$ & OR (95\% Cl) \\
\hline Total & & 2,086 & $368(19.2)^{\dagger}$ & & $255(12.3)^{\dagger}$ & \\
\hline Sex & $\begin{array}{l}\text { Female } \\
\text { Male }\end{array}$ & $\begin{array}{l}1,034(49.6) \\
1,052(50.4)\end{array}$ & $\begin{array}{l}188(19.8) \\
180(18.6)\end{array}$ & $\begin{array}{c}\text { Reference } \\
0.93(0.74-1.16)\end{array}$ & $\begin{array}{l}136(13.2) \\
133(12.6)\end{array}$ & $\begin{array}{c}\text { Reference } \\
0.95(0.74,1.23)\end{array}$ \\
\hline \multirow[t]{2}{*}{ Ethnicity } & $\begin{array}{l}\text { Non-Hispanic } \\
\text { white }\end{array}$ & $732(35.1)$ & 160 (23.2) & $1.56(1.22-1.99)$ & $118(16.1)$ & $1.66(1.26-2.19)$ \\
\hline & $\begin{array}{l}\text { Hispanic white } \\
\text { Other }\end{array}$ & $\begin{array}{r}1,078(51.7) \\
276(13.2)\end{array}$ & $\begin{array}{r}161(16.3) \\
47(19.5)\end{array}$ & $\begin{array}{c}\text { Reference } \\
1.25(0.87-1.79)\end{array}$ & $\begin{array}{r}112(10.4) \\
39(14.1)\end{array}$ & $\begin{array}{c}\text { Reference } \\
1.42(0.96-2.09)\end{array}$ \\
\hline Parental education & $\begin{array}{l}<12 \text { th grade } \\
12 \text { th grade } \\
\text { Some college } \\
\text { College degree } \\
\text { Some graduate } \\
\text { school }\end{array}$ & $\begin{array}{l}387(20.1) \\
312(16.2) \\
720(37.4) \\
258(13.4) \\
246(12.8)\end{array}$ & $\begin{array}{r}47(13.4) \\
59(20.4) \\
137(20.4) \\
57(24.0) \\
42(18.4)\end{array}$ & $\begin{array}{c}\text { Reference } \\
1.66(1.09-2.53) \\
1.66(1.16-2.38) \\
2.04(1.33-3.13) \\
1.47(0.93-2.31)\end{array}$ & $\begin{array}{r}28(7.3) \\
42(13.5) \\
110(15.3) \\
43(16.7) \\
33(13.4)\end{array}$ & $\begin{array}{c}\text { Reference } \\
2.00(1.21-3.30) \\
2.31(1.49-3.57) \\
2.56(1.54-4.24) \\
1.98(1.16-3.37)\end{array}$ \\
\hline $\begin{array}{l}\text { Secondhand smoke } \\
\text { in home }\end{array}$ & $\begin{array}{l}\text { No } \\
\text { Yes }\end{array}$ & $\begin{array}{c}1,964(94.3) \\
119(5.7)\end{array}$ & $\begin{array}{r}332(18.3) \\
36(32.1)\end{array}$ & $\begin{array}{c}\text { Reference } \\
2.11(1.39-3.19)\end{array}$ & $\begin{array}{r}252(12.9) \\
17(14.3)\end{array}$ & $\begin{array}{c}\text { Reference } \\
1.13(0.67-1.92)\end{array}$ \\
\hline Cigarette use & $\begin{array}{l}\text { Never } \\
\text { Past } \\
\text { Current }\end{array}$ & $\begin{array}{r}1,693(81.3) \\
271(13.0) \\
119(5.71)\end{array}$ & $\begin{array}{r}271(17.3) \\
58(24.2) \\
39(35.5)\end{array}$ & $\begin{array}{c}\text { Reference } \\
1.53(1.11-2.11) \\
2.63(1.74-3.98)\end{array}$ & $\begin{array}{r}196(11.6) \\
46(17.0) \\
27(22.7)\end{array}$ & $\begin{array}{c}\text { Reference } \\
1.56(1.10-2.21) \\
2.24(1.42-3.52)\end{array}$ \\
\hline
\end{tabular}

Definition of abbreviations: $\mathrm{Cl}=$ confidence interval; $\mathrm{OR}=$ odds ratio.

*Denominator ( $n=2,086$ with information on electronic cigarette use and either outcome) varies because of missing values in covariates.

${ }^{\dagger} \mathrm{n}=1,922$ for bronchitic symptoms with complete outcome information, $\mathrm{n}=2,083$ for wheeze. 


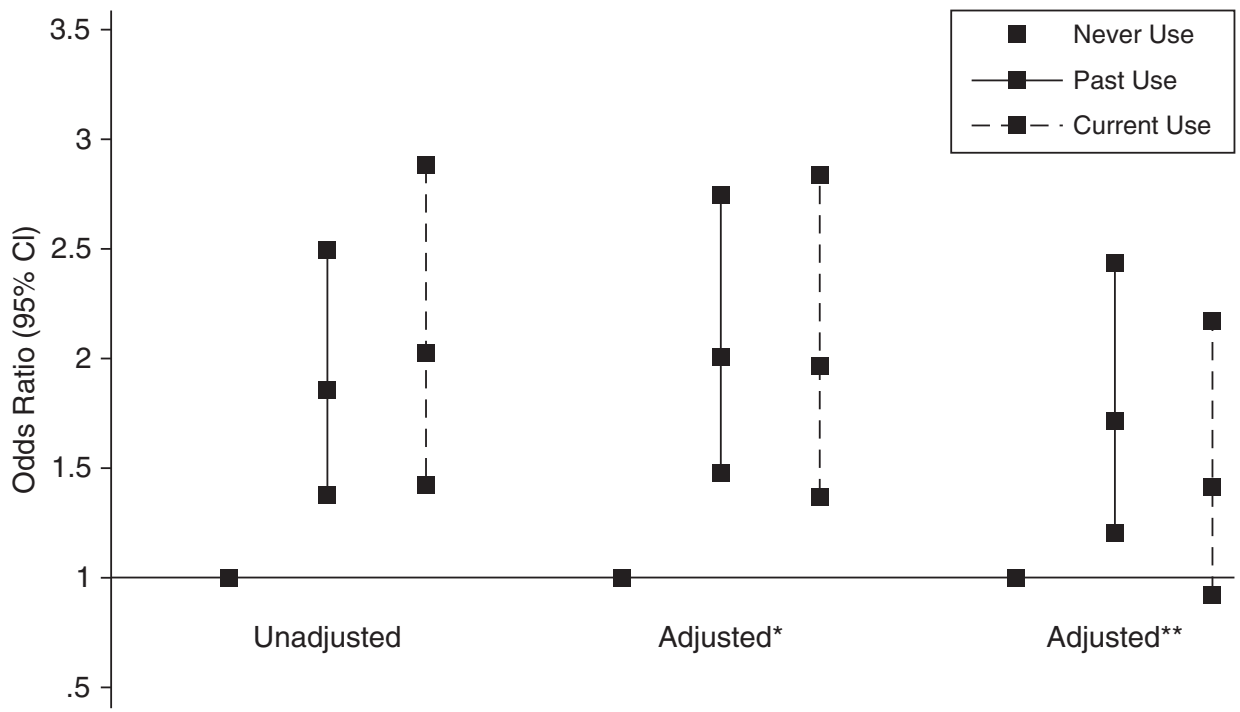

Figure 1. Association of current and past electronic cigarette use with bronchitis, adjusted for sociodemographic characteristics, smoking history, and secondhand tobacco smoke exposure $(n=1,922)$. *Adjusted for sex, ethnicity, parental education, and community. ${ }^{\star *}$ Adjusted for sex, ethnicity, parental education, community, secondhand smoke, and lifetime number of cigarettes smoked. $\mathrm{Cl}=$ confidence interval.

association with e-cigarette use frequency was not confounded by demographic characteristics, but was attenuated by additional adjustment for SHS exposure and lifetime number of cigarettes smoked (OR, 1.37; 95\% CI, 0.79-2.37 for $1-2 \mathrm{~d}$ of use) (OR, 1.64; 95\% CI, 0.88-3.05 for $\geqslant 3 \mathrm{~d}$ of use) and the trend was no longer significant $(P$ for trend 0.09).

In sensitivity analyses restricted to never-cigarette smokers, the risks of bronchitic symptoms associated with past and current e-cigarette use were not as large as observed in the unadjusted analysis of all study participants but were unchanged by adjustment for demographic characteristics and SHS exposure (OR, 1.70; 95\% CI, 1.11-2.59 for past e-cigarette use after adjustment) (OR, 1.52; 95\% CI, 0.89-2.61 for current e-cigarette use after adjustment) (Figure 3). Effect estimates were similar in magnitude to those observed in models of the entire population adjusted for lifetime smoking history shown in Figure 1. In additional sensitivity analyses the pattern of effect estimates for the association of bronchitic symptoms with e-cigarette use was similar after adjustment for bronchitic symptoms in 2010 and in analyses restricted to adolescents with no bronchitic symptoms in 2010 (results not shown).

Wheeze was associated with current (OR, 1.86; 95\% CI, 1.28-2.71) but not with past use of e-cigarettes (OR, 1.02; 95\% CI,
0.70-1.49) (Figure 4, left). The effect of current e-cigarette use was not confounded by sociodemographic characteristics but was markedly attenuated by adjustment for SHS exposure and lifetime number of cigarettes smoked (OR, 1.24; 95\% CI, 0.78-1.98), and after adjustment the association of past use of e-cigarettes with wheeze became negative (OR, 0.70; 95\% CI, 0.45-1.10). The magnitude of effect estimates for e-cigarette exposure in analyses restricted to neversmokers was similar to those found in the entire population after adjustment for sociodemographic characteristics, smoking history, and SHS exposure (Figure 4, right). The frequency of current use of e-cigarettes was not associated with wheeze in either unadjusted or adjusted models (results not shown). In additional sensitivity analyses, we examined associations of e-cigarette use with more severe wheeze in the past year, based on attacks of wheeze, sleep disturbance, or shortness of breath caused by wheeze; the pattern of associations was similar to that observed with any wheeze in the previous year (results not shown).

\section{Discussion}

Bronchitic symptoms were associated with use of e-cigarettes among adolescents. Associations with past, but not current, use remained statistically significant after adjustment for use of cigarettes and other combustible tobacco products, sociodemographic characteristics, and respiratory risk factors in the home, including SHS exposure. Bronchitic symptoms were also associated with frequency of current use, based on number of days of e-cigarette use in the past month, but these effect estimates were markedly attenuated and not statistically significant after adjustment for lifetime number of cigarettes smoked and SHS exposure. There were no significant associations of wheeze, a marker of allergic airway disease, with use of e-cigarettes. These findings contribute data to the ongoing debate about the health effects of e-cigarettes that has largely occurred in the absence of evidence either of safety or of harm, and the results are potentially informative for clinicians asked to advise patients and parents about the hazards of e-cigarette use.

Bronchitis and chronic bronchitic symptoms are common and have been associated with substantial clinical morbidity and economic cost (14, 24-26). Bronchitis or questionnaire-based report of persistent cough and phlegm are relatively imprecise outcomes and likely represent a heterogeneous complex of conditions, including chronic, indolent respiratory illness, asthma exacerbation, or chronic airway inflammation. These outcomes might also reflect repeated acute exacerbations, including acute bronchitis that has been reported to persist for several 


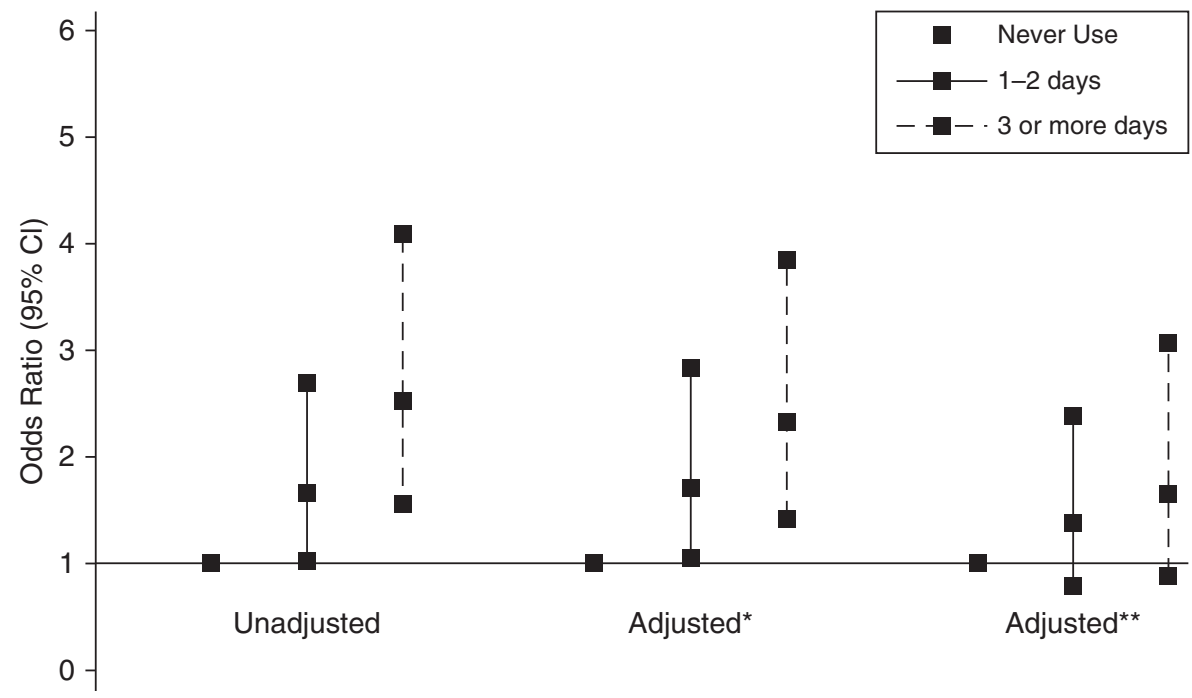

Figure 2. Association of number of days of current electronic cigarette use in prior month with bronchitis, adjusted for sociodemographic characteristics, smoking history, and secondhand tobacco smoke exposure in the Children's Health Study $(n=1,640)$. *Adjusted for sex, ethnicity, parental education, and community. ${ }^{* *}$ Adjusted for sex, ethnicity, parental education, community, secondhand smoke, and lifetime number of cigarettes smoked. $\mathrm{Cl}=$ confidence interval.

weeks and to have a marked impact on quality of life, in adults and in children $(14,27)$. Bronchitis and bronchitic symptoms have shown robust associations with diverse respiratory hazards in previous epidemiologic studies $(15,17-19)$, including with childhood smoking and exposure to SHS

$(17,18)$. The magnitude of estimated effect we observed was only a little smaller than that previously reported to occur as a result of occasional smoking in an adolescent population (28). Therefore, if causal, the observed association between bronchitic symptoms and e-cigarettes could have clinical, public

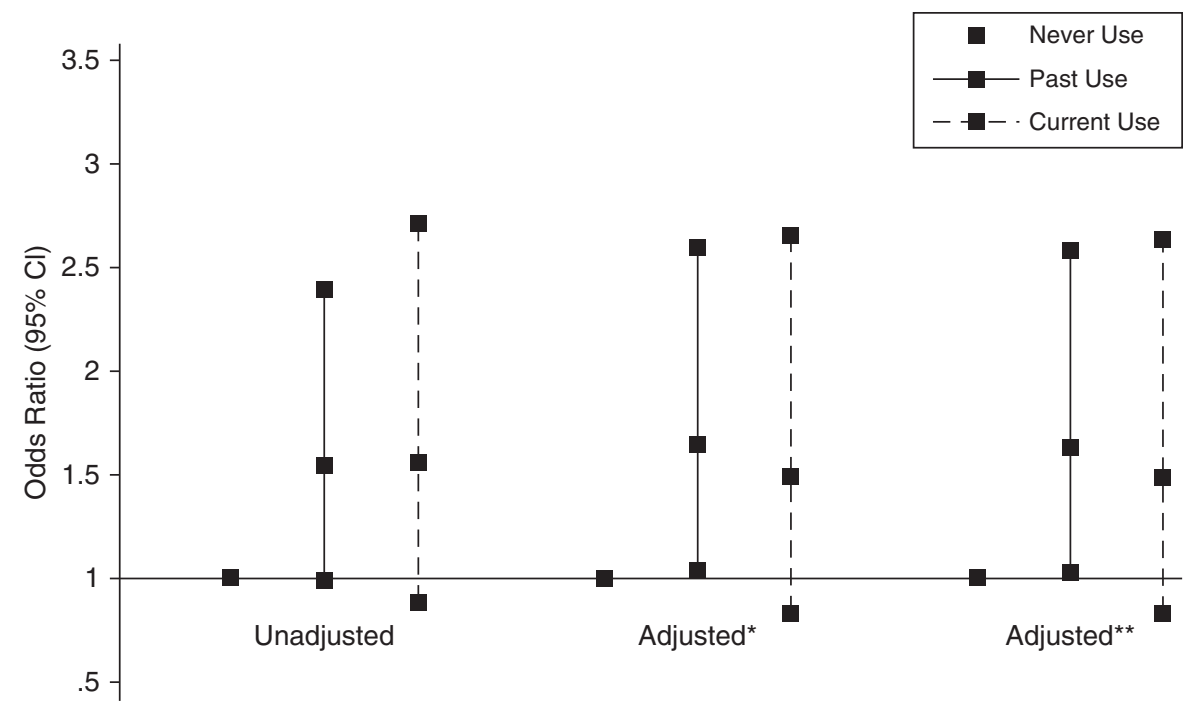

Figure 3. Association of current and past electronic cigarette use with bronchitis among never-smokers, adjusted for sociodemographic characteristics, smoking history, and secondhand tobacco smoke exposure $(n=1,570)$. *Adjusted for sex, ethnicity, parental education, and community. ${ }^{\star \star}$ Adjusted for sex, ethnicity, parental education, community, and secondhand smoke. $\mathrm{Cl}=$ confidence interval. health, economic, and policy implications.

Results were consistent with those of a cross-sectional study of Chinese adolescents, among whom a greater than twofold increased risk of bronchitic symptoms associated with e-cigarette use was observed among never-smokers (11). These associations are plausible based on the known pulmonary toxicity of e-cigarette aerosol composition, including glycerol vapor, nicotine, and other irritants that have been associated with bronchitic and other respiratory symptoms (3, 6-8, 29-33). Flavorings, including diacetyl and related diketone compounds that have a sweet or buttery flavor, have caused bronchiolitis obliterans, an obstructive lung disease, in exposed workers and in animal models (5). These diketone flavoring compounds have been measured in e-cigarette liquids at concentrations of public health concern $(34,35)$. E-cigarette solutions produced cytotoxicity and proinflammatory effects that varied markedly across brands and solutions, depending at least in part on flavoring, in in vitro models using cells relevant to the lung $(36,37)$. A case report of lipoid pneumonia was attributed to recurrent exposure to glycerin-based oils found in e-cigarette nicotine vapor (38).

A previous study of Korean high school students found increased risk of asthma and more severe asthma in the previous year to be associated with e-cigarette use (12). E-cigarette aerosol exposure also increased allergeninduced airway inflammation and hyperresponsiveness in an experimental study in mice (39). In addition, acute effects of e-cigarette vapor inhalation on fractional excretion of nitric oxide, a marker of airway inflammation, have been observed (although the direction of effect has not been consistent) $(10,40)$.

However, we found no association of e-cigarette use with wheeze or wheeze severity, markers of asthma activity. It is possible that youth with asthma were more likely to self-select not to use e-cigarettes because of their disease. However, history of asthma neither confounded nor modified the association of e-cigarette use with bronchitic symptoms, which might be expected to be subject to similar self-selection. 


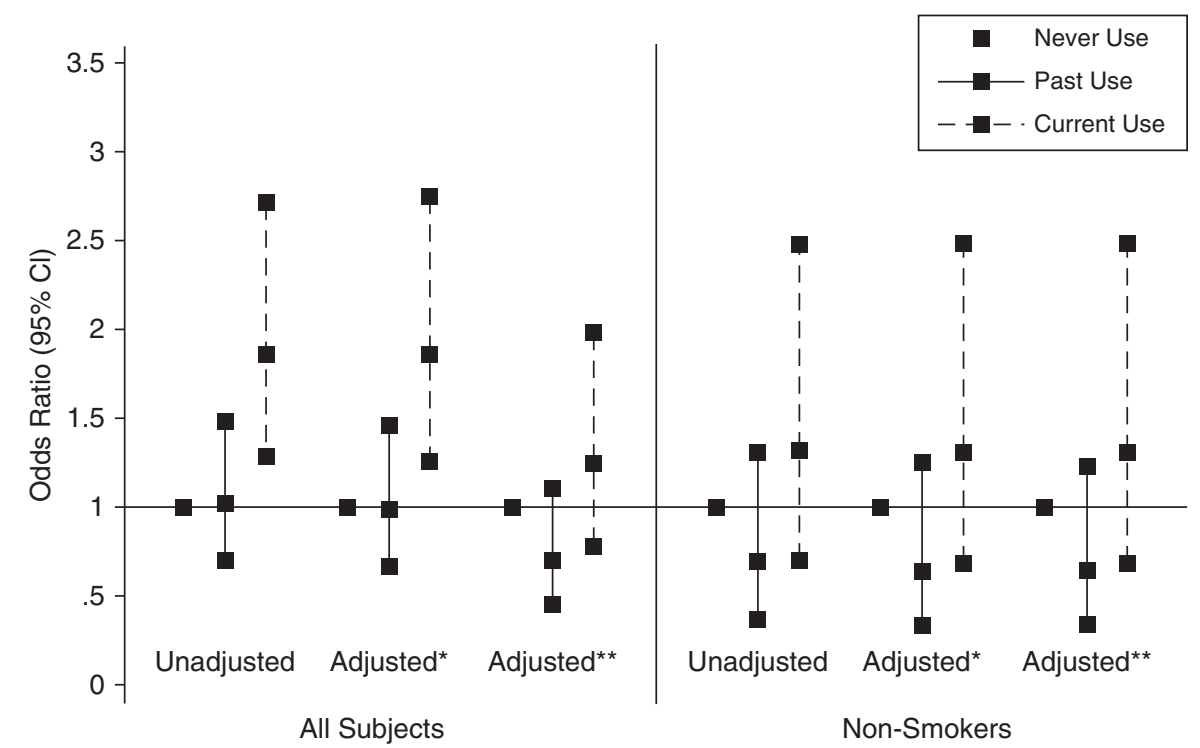

Figure 4. Association of current and past electronic cigarette use with wheeze, adjusted for sociodemographic characteristics, smoking history, and secondhand tobacco smoke exposure (left, $n=2,083$ ), and restricted to never-smokers (right; $n=1,689$ ). *Adjusted for sex, ethnicity, parental education, and community. ${ }^{* *}$ Adjusted for sex, ethnicity, parental education, community, secondhand smoke, and (left panel) lifetime number of cigarettes smoked. $\mathrm{Cl}=$ confidence interval.

The study has several strengths, including well-characterized covariates of respiratory symptoms in a large ethnically diverse sample of adolescents. Limitations to the inference of a causal relationship between past e-cigarette use and bronchitic symptoms include the possibility that residual confounding by smoking could have explained the association with past use, if cigarette smoking were not accurately measured, because associations of bronchitic symptoms with e-cigarette use were attenuated by adjustment for smoking history. However, low rates of smoking in this cohort and substantial numbers of e-cigarette users who were never-smokers made it possible to disentangle the independent associations of each exposure. It is unlikely that cigarette use explained the results, because an association of bronchitic symptoms with past use of e-cigarettes was also observed among never-smokers and was similar in magnitude to the estimated effects of past e-cigarette use adjusted for cigarette use in the entire population sample. Effects were also robust to additional adjustment for a large number of sociodemographic factors, other combustible tobacco product use, asthma, and other housing characteristics (listed in Tables 1 and E1).
Although the adjusted association of bronchitic symptoms with current e-cigarette use was not statistically significant, the strength of the association was only modestly weaker than with past users and the difference in estimates for past and current use was not statistically significant. It is also possible that those adolescents who experienced symptoms after trying e-cigarettes chose to stop, becoming past users.

It is possible that study participants with preexisting symptoms and an interest in using tobacco products might have used e-cigarettes because of a perception that they were less toxic than cigarettes. However, adjustment for perception of e-cigarette harm did not confound the association of past e-cigarette use with bronchitic symptoms.

Only the 2014 questionnaire asked about use of e-cigarettes and tobacco products other than cigarettes. However, information on bronchitic symptoms collected in 2010 tracked over time (see Table E1), so adjusting the observed cross-sectional associations for bronchitic symptoms in previous years provided an opportunity to account for unmeasured determinants of symptoms. Because there was little adolescent e-cigarette use in the
United States in 2010 and likely little use of other tobacco products (at cohort average age 13), by adjusting for 2010 symptoms it was possible to assess prospectively the change in symptoms associated with e-cigarette use. It is, therefore, more likely that the observed (2014) relationship of bronchitic symptoms with e-cigarette use was causal, because the e-cigarette effect estimates were unchanged after adjustment for 2010 symptoms and after restriction to adolescents with no bronchitic symptoms in 2010. However, the prevalence of 2010 bronchitic symptoms was also associated with (subsequent) e-cigarette use.

Therefore, the possibility that the 2014 cross-sectional associations could be explained by unmeasured confounders associated with e-cigarette use cannot be excluded. Further longitudinal follow-up of this and other cohort studies of respiratory health in children, and complementary experimental studies, are needed to elucidate these relationships.

Several public health and research organizations, including the Forum of International Respiratory Societies, the American Association for Cancer Research, and the American Society of Clinical Oncology (41), have proposed regulation to restrict or ban e-cigarettes until there is more evidence of the safety of e-cigarette use (42). The Food and Drug Administration recently finalized a rule to extend its authority over all tobacco products, including e-cigarettes (43). This rule will prohibit the sale of e-cigarette products to persons younger than age 18 years and will prohibit sale of e-cigarettes in vending machines and the distribution of free samples. Our results suggest that reducing e-cigarette use in youth may reduce morbidity. However, because e-cigarette use is still new, there has been little study of its chronic effects. Additional epidemiologic and toxicologic investigation of effects of chronic e-cigarette exposure is urgently needed.

Author disclosures are available with the text of this article at www.atsjournals.org.

Acknowledgment: Steve Howland helped develop questionnaires, and he and Edward Avol organized and supervised the field collection of data. 


\section{References}

1. Singh T, Arrazola RA, Corey CG, Husten CG, Neff LJ, Homa DM, King BA. Tobacco use among middle and high school students-United States, 2011-2015. MMWR Morb Mortal Wkly Rep 2016;65:361-367.

2. Zhu SH, Sun JY, Bonnevie E, Cummins SE, Gamst A, Yin L, Lee M. Four hundred and sixty brands of e-cigarettes and counting: implications for product regulation. Tob Control 2014;23:iii3-iii9.

3. Callahan-Lyon P. Electronic cigarettes: human health effects. Tob Control 2014;23:ii36-ii40.

4. Rowell TR, Tarran R. Will chronic e-cigarette use cause lung disease? Am J Physiol Lung Cell Mol Physiol 2015;309:L1398-L1409.

5. Barrington-Trimis JL, Samet JM, McConnell R. Flavorings in electronic cigarettes: an unrecognized respiratory health hazard? JAMA 2014; 312:2493-2494.

6. Talih S, Balhas Z, Salman R, Karaoghlanian N, Shihadeh A. "Direct dripping": a high-temperature, high-formaldehyde emission electronic cigarette use method. Nicotine Tob Res 2016;18:453-459.

7. Jensen RP, Luo W, Pankow JF, Strongin RM, Peyton DH. Hidden formaldehyde in e-cigarette aerosols. N Engl J Med 2015;372:392-394.

8. Saffari A, Daher N, Ruprecht A, De Marco C, Pozzi P, Boffi R, Hamad SH, Shafer MM, Schauer JJ, Westerdahl D, et al. Particulate metals and organic compounds from electronic and tobacco-containing cigarettes: comparison of emission rates and secondhand exposure. Environ Sci Process Impacts 2014;16:2259-2267.

9. Lerner CA, Sundar IK, Yao H, Gerloff J, Ossip DJ, Mclntosh S, Robinson R, Rahman I. Vapors produced by electronic cigarettes and e-juices with flavorings induce toxicity, oxidative stress, and inflammatory response in lung epithelial cells and in mouse lung. PLoS One 2015;10:e0116732.

10. Marini S, Buonanno G, Stabile L, Ficco G. Short-term effects of electronic and tobacco cigarettes on exhaled nitric oxide. Toxicol Appl Pharmacol 2014;278:9-15.

11. Wang MP, Ho SY, Leung LT, Lam TH. Electronic cigarette use and respiratory symptoms in Chinese adolescents in Hong Kong. JAMA Pediatr 2016;170:89-91.

12. Cho JH, Paik SY. Association between electronic cigarette use and asthma among high school students in South Korea. PLoS One 2016;11:e0151022.

13. McConnell R, Berhane K, Yao L, Jerrett M, Lurmann F, Gilliland F, Künzl N, Gauderman J, Avol E, Thomas D, et al. Traffic, susceptibility, and childhood asthma. Environ Health Perspect 2006;114:766-772.

14. Brandt S, Perez L, Künzli N, Lurmann F, Wilson J, Pastor M, McConnell R. Cost of near-roadway and regional air pollution-attributable childhood asthma in Los Angeles County. J Allergy Clin Immunol 2014:134:1028-1035.

15. McConnell R, Berhane K, Gilliland F, Molitor J, Thomas D, Lurmann F, Avol E, Gauderman WJ, Peters JM. Prospective study of air pollution and bronchitic symptoms in children with asthma. Am J Respir Crit Care Med 2003;168:790-797.

16. Burke H, Leonardi-Bee J, Hashim A, Pine-Abata H, Chen Y, Cook DG, Britton JR, McKeever TM. Prenatal and passive smoke exposure and incidence of asthma and wheeze: systematic review and metaanalysis. Pediatrics 2012;129:735-744.

17. National Center for Chronic Disease Prevention and Health Promotion. The health consequences of smoking- 50 years of progress: a report of the Surgeon General. Atlanta, GA: Centers for Disease Control and Prevention; 2014.

18. Chen JM, Hwang BF, Chen YC, Lee YL. Active smoking, environmental tobacco smoke and bronchitic symptoms among adolescents in Taiwan: a prospective cohort study. Prev Med 2014;65:116-121.

19. Forey BA, Thornton AJ, Lee PN. Systematic review with meta-analysis of the epidemiological evidence relating smoking to COPD, chronic bronchitis and emphysema. BMC Pulm Med 2011;11:36.

20. Asher MI, Keil U, Anderson HR, Beasley R, Crane J, Martinez F, Mitchell EA, Pearce N, Sibbald B, Stewart AW, et al. International Study of Asthma and Allergies in Childhood (ISAAC): rationale and methods. Eur Respir J 1995;8:483-491.

21. McConnell R, Islam T, Shankardass K, Jerrett M, Lurmann F, Gilliland F, Gauderman J, Avol E, Künzli N, Yao L, et al. Childhood incident asthma and traffic-related air pollution at home and school. Environ Health Perspect 2010;118:1021-1026.
22. Arrazola RA, Singh T, Corey CG, Husten CG, Neff LJ, Apelberg BJ, Bunnell RE, Choiniere CJ, King BA, Cox S, et al.; Centers for Disease Control and Prevention (CDC). Tobacco use among middle and high school students-United States, 2011-2014. MMWR Morb Mortal Wkly Rep 2015;64:381-385

23. McConnell R, Berhane K, Molitor J, Gilliland F, Künzli N, Thorne PS, Thomas D, Gauderman WJ, Avol E, Lurmann F, et al. Dog ownership enhances symptomatic responses to air pollution in children with asthma. Environ Health Perspect 2006;114:1910-1915.

24. Morgan WJ, Taussig LM. The chronic bronchitis complex in children. Pediatr Clin North Am 1984;31:851-864.

25. Shields MD, Doherty GM. Chronic cough in children. Paediatr Respir Rev 2013;14:100-105; quiz 106, 137-108.

26. Klein RB, Huggins BW. Chronic bronchitis in children. Semin Respir Infect 1994:9:13-22.

27. Verheij T, Hermans J, Kaptein A, Mulder J. Acute bronchitis: course of symptoms and restrictions in patients' daily activities. Scand J Prim Health Care 1995;13:8-12.

28. Lam TH, Chung SF, Betson CL, Wong CM, Hedley AJ. Respiratory symptoms due to active and passive smoking in junior secondary school students in Hong Kong. Int J Epidemiol 1998;27:41-48.

29. Lee LY, Gu Q. Cough sensors: IV. Nicotinic membrane receptors on cough sensors. Handbook Exp Pharmacol 2009;187:77-98.

30. Antonini JM, Taylor MD, Zimmer AT, Roberts JR. Pulmonary responses to welding fumes: role of metal constituents. $J$ Toxicol Environ Health A 2004;67:233-249.

31. Kosmider L, Sobczak A, Fik M, Knysak J, Zaciera M, Kurek J, Goniewicz ML. Carbonyl compounds in electronic cigarette vapors: effects of nicotine solvent and battery output voltage. Nicotine Tob Res 2014;16:1319-1326.

32. Zhang Y, Sumner W, Chen DR. In vitro particle size distributions in electronic and conventional cigarette aerosols suggest comparable deposition patterns. Nicotine Tob Res 2013;15:501-508.

33. Li N, Sioutas C, Cho A, Schmitz D, Misra C, Sempf J, Wang M, Oberley T, Froines J, Nel A. Ultrafine particulate pollutants induce oxidative stress and mitochondrial damage. Environ Health Perspect 2003;111:455-460.

34. Farsalinos KE, Kistler KA, Gillman G, et al. Evaluation of electronic cigarette liquids and aerosol for the presence of selected inhalation toxins. Nicotine Tob Res 2015;17:168-174.

35. Hubbs AF, Cummings KJ, McKernan LT, Dankovic DA, Park RM, Kreiss K. Comment on Farsalinos et al., "Evaluation of electronic cigarette liquids and aerosol for the presence of selected inhalation toxins". Nicotine Tob Res 2015;17:1288-1289.

36. Bahl V, Lin S, Xu N, Davis B, Wang YH, Talbot P. Comparison of electronic cigarette refill fluid cytotoxicity using embryonic and adult models. Reprod Toxicol 2012;34:529-537.

37. Cervellati F, Muresan XM, Sticozzi C, Gambari R, Montagner G, Forman HJ, Torricelli C, Maioli E, Valacchi G. Comparative effects between electronic and cigarette smoke in human keratinocytes and epithelial lung cells. Toxicol In Vitro 2014;28: 999-1005.

38. McCauley L, Markin C, Hosmer D. An unexpected consequence of electronic cigarette use. Chest 2012;141:1110-1113.

39. Lim HB, Kim SH. Inhalation of e-cigarette cartridge solution aggravates allergen-induced airway inflammation and hyper-responsiveness in mice. Toxicol Res 2014;30:13-18.

40. Vardavas $\mathrm{Cl}$, Anagnostopoulos N, Kougias M, Evangelopoulou V, Connolly GN, Behrakis PK. Short-term pulmonary effects of using an electronic cigarette: impact on respiratory flow resistance, impedance, and exhaled nitric oxide. Chest 2012;141:1400-1406.

41. AACR. ASCO call for e-cigarette regulation. Cancer Discov 2015;5:219.

42. Schraufnagel DE, Blasi F, Drummond MB, Lam DC, Latif E, Rosen MJ, Sansores R, Van Zyl-Smit R; Forum of International Respiratory Societies. Electronic cigarettes. A position statement of the forum of international respiratory societies. Am J Respir Crit Care Med 2014; 190:611-618.

43. Food and Drug Administration, HHS. Deeming tobacco products to be subject to the Federal Food, Drug, and Cosmetic Act, as Amended by the Family Smoking Prevention and Tobacco Control Act; restrictions on the sale and distribution of tobacco products and required warning statements for tobacco products. Final rule. Fed Regist 2016;81:28975-28981. 